\title{
Flow field of Kronebreen, Svalbard, using repeated Landsat 7 and ASTER data
}

\author{
Andreas K $\mathrm{A} \ddot{A B},{ }^{1 *}$ Bernard LEFAUCONNIER, ${ }^{2}$ Kjetil MELVOLD ${ }^{3}$ \\ ${ }^{1}$ Department of Geography, University of Zürich-Irchel, Winterthurerstrasse 190, CH-8057 Zürich, Switzerland \\ E-mail: kaeaeb@geo.uio.no \\ ${ }^{2}$ Le Mollard, 38700 Le Sappey-en-Chartreuse, France \\ ${ }^{3}$ Department of Geosciences, University of Oslo, N-0371 Oslo, Norway
}

\begin{abstract}
Knowledge about the spatio-temporal distribution of fast-flowing Arctic glaciers is still limited. Kronebreen, Svalbard, in particular, includes the confluence - and the dynamic interplay - of the fast-flowing Kronebreen and the currently slow-flowing Kongsvegen. In this study, image-matching techniques on the basis of repeated Landsat 7 Enhanced Thematic Mapper Plus (ETM+) pan and Advanced Spaceborne Thermal Emission and Reflection Radiometer (ASTER) satellite data are applied in order to derive surface velocity fields of the lowermost $10 \mathrm{~km}$ of Kronebreen for the annual periods $1999 / 2000,2000 / 01,2001 / 02$ and a 40 day period around July 2001. This work perfectly complements differential synthetic aperture radar interferometry (DInSAR) studies available for Kronebreen. A complete surface velocity field is now available from combining the DInSAR studies for the upper part of the glacier and the optical image-matching study presented here. The data obtained within this study are also compared to velocity data of 1964, 1986, 1990 and 1996. As also suggested by previous studies, a significant spatio-temporal variability of the spring/summer and annual ice speeds becomes evident.
\end{abstract}

\section{INTRODUCTION}

Knowledge about the spatio-temporal distribution of flow on fast-flowing Arctic glaciers is still limited, but the flow mechanisms are crucial factors in determining mass balance and thus in controlling the reaction of these glaciers to climate changes, in particular when these glaciers are calving (calving rates). Kronebreen, Svalbard, in particular, includes the confluence - and the dynamic interplay - of the fast-flowing Kronebreen and the currently slow-flowing Kongsvegen (Fig. 1). Both are tidewater calving glaciers. Kongsvegen is known to have a polythermal regime with a cold surface layer underlain by a warm basal layer in the ablation area (Björnsson and others, 1996). Kronebreen experienced a major surge in 1868 or 1869 (Liestøl, 1988; Hagen and others, 1993; M.J. Hambrey and others, http:// boris.qub.ac.uk/ggg/papers/full/1999/rp071999/rp07.html). The following front retreat of $>4 \mathrm{~km}$ was interrupted by a surge of Kongsvegen in 1948 that led to an advance of about $1.5 \mathrm{~km}$ into the sea (Melvold and Hagen, 1998; M.J. Hambrey and others, http://boris.qub.ac.uk/ggg/papers/ full/1999/rp071999/rp07.html). Since then, the joint front of both glaciers has been continuously retreating for $>4 \mathrm{~km}$. The glacier bed is partially below sea level along a stretch of about $7 \mathrm{~km}$ upstream of the front (Lefauconnier, 1987; Lefauconnier and others, 1994).

A first goal of this study is to evaluate combined imagematching techniques based on the Advanced Spaceborne Thermal Emission and Reflection Radiometer (ASTER) and Landsat 7 Enhanced Thematic Mapper Plus (ETM+) instruments to derive both year-to-year and summer velocities. This aspect of the study is also connected to the Global Land Ice Measurements from Space (GLIMS) project which aims, among other things, at measuring glacier speed on a global scale (Bishop and others, 2004). A second goal is to provide

*Present address: Department of Geosciences, University of Oslo, PO Box 1047 Blindern, NO-0316 Oslo, Norway. data about the current dynamics of Kronebreen and to compare them to previous studies from the mid-60s on.

In this study, the annual surface velocity field of the lowermost $10 \mathrm{~km}$ of Kronebreen is derived through image matching for 1999/2000, 2000/01 and 2001/02. In addition, the velocity field for a 40 day period around July 2001 was measured. Such work perfectly complements differential synthetic aperture radar interferometry (DInSAR), which was previously applied to Kronebreen (Wangensteen and others, 1999; Lefauconnier and others, 2001; Eldhuset and others, 2003). DInSAR provides valuable results for the upper part of the glacier, but suffers from decorrelation on the fast-flowing

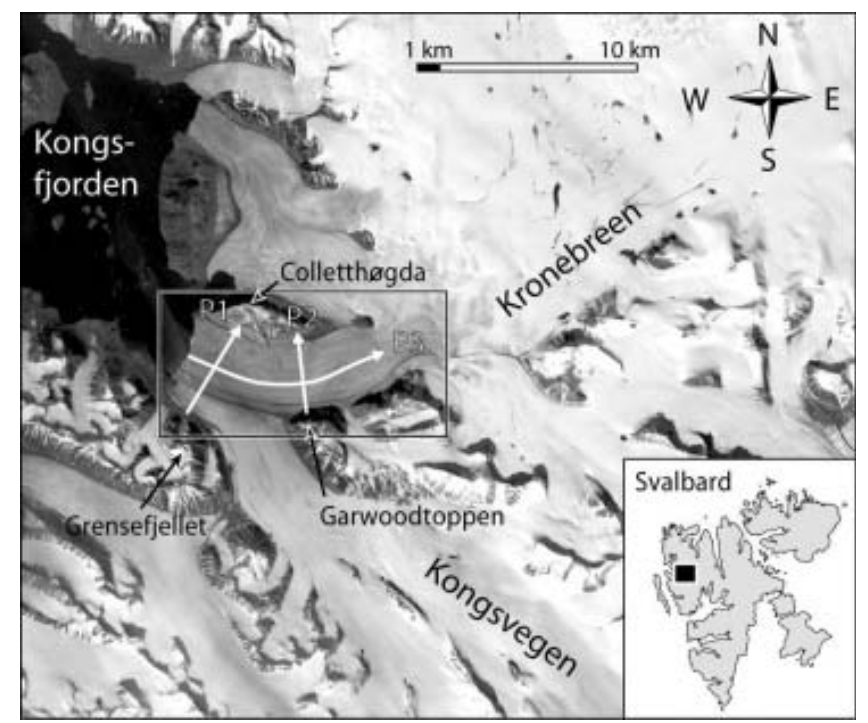

Fig. 1. Section of a Landsat 7 ETM+ scene of 10 July 1999 showing parts of Kronebreen and Kongsvegen, Svalbard. The black rectangle marks the glacier section studied (cf. Figs 2 and 3). The white lines P1-P3 indicate the location of profiles (cf. Figs 5-7). 




Fig. 2. Surface velocity field for a section of Kronebreen, derived from ASTER imagery of 26 June and 6 August 2001. Isolines indicate ice speed in metres per year. The surface velocities of Kongsvegen are too small to be measured from repeated satellite imagery. Underlying ASTER image of 6 August 2001.

lower part. Furthermore, area-wide satellite image matching complements the available terrestrial measurements, which gave precise velocity data for individual points and profiles. In detail, the glacier flow obtained in this study is compared to surface velocity measurements for the lower section of Kronebreen from:

terrestrial photogrammetry in the period 1962-65 (e.g. Pillewizer and Voigt, 1968),

terrestrial photogrammetry in the period 1983-86 (Lefauconnier, 1987),

repeated Système Probatoire pour I'Observation de la Terre (SPOT) imagery of 1986 (Lefauconnier and others, 1994; Rolstad, 1995),

terrestrial photogrammetry and stake measurements for 1990 (Melvold, 1992).

We do not compare our data with DInSAR measurements from Eldhuset and others (2003) (also presented in König and others, 2001) based on ERS-1/-2 tandem-mission interferograms over July 1995-May 1996, because they note problems with coherence and phase unwrapping in the lower, fast-flowing part of Kronebreen.

In the following, the applied satellite imagery and the processing steps towards deriving horizontal velocity fields are described. The results obtained are discussed and compared to the studies listed above. We end with conclusions on both the dynamics of Kronebreen and the methods applied.

\section{DATA AND METHODS}

The methods used in this study follow, for the most part, Kääb (2002, 2004) and Kääb and others (2003). In the sections following, the focus is therefore rather on nonstandard aspects arising from the Kronebreen study in particular.

Our velocity measurements are based on a Landsat ETM+ scene of 10 July 1999 and ASTER scenes of 17 August 2000, 26 June 2001, 6 August 2001 and 12 July 2002. Deriving surface displacements from repeated Landsat data alone does not necessarily require georeferencing and orthorectification of the exploited imagery because these data are taken with the same acquisition geometry (orbit, pointing angle, etc.) and simple co-registration might be sufficient to account for offsets between the repeated images (e.g. Scambos and others, 1992; Skvarca and others, 2003; cf. Dowdeswell and Benham, 2003 for ASTER). The same applies to comparably simple topography that can be approximated by an (inclined) plane. These preconditions for skipping image orientation and topographic correction are not fulfilled when combining satellite data from different sensors with different imaging geometry, and/or observing over more complex topography. The Terra spacecraft, which carries ASTER, uses approximately the same orbit as Landsat 7, but ASTER can be pointed up to $\pm 8.5^{\circ}$ cross-track $\left( \pm 24^{\circ}\right.$ for the visible and near-infrared sensor) (ERSDAC, 1999a, b; Kääb and others, 2003). Indeed, the target area of our study is sampled from different viewing angles and orbits of the ASTER scenes used. The ASTER and Landsat 7 ETM+ scenes were therefore oriented using ground-control points from the 1:100000 topographic map of Svalbard compiled by the Norwegian Polar Institute.

A digital terrain model (DTM) was then computed from the ASTER nadir band $3 \mathrm{~N}$ of 17 August 2000 and the corresponding back-looking stereo-band $3 \mathrm{~B}$ (Kääb and others, 2003; Kääb, 2005). It turned out that generation of $60 \mathrm{~m}$ resolution DTMs produced a large number of errors. Despite sufficient optical contrast on the lower part of Kronebreen, the high self-similarity of many seracs and other crevasse features lead to numerous matching errors during the DTM generation process. A multi-level approach for DTM production was therefore chosen including also DTMs matched at 120 and $240 \mathrm{~m}$ DTM resolution. These coarse DTMs showed much fewer matching errors due to the reduced feature similarity in the coarser levels of the image pyramid that formed the base for the corresponding coarser DTMs (Kääb, 2004, 2005). The three DTM levels obtained were then combined so that individual elevation values of the higher-resolution level replaced the lower-resolution level wherever the differences between the two levels did not exceed a certain error threshold (here $30 \mathrm{~m}$ ).

From the satellite scenes, from their orientation parameters and from the ASTER DTM, orthoimages of the lower 


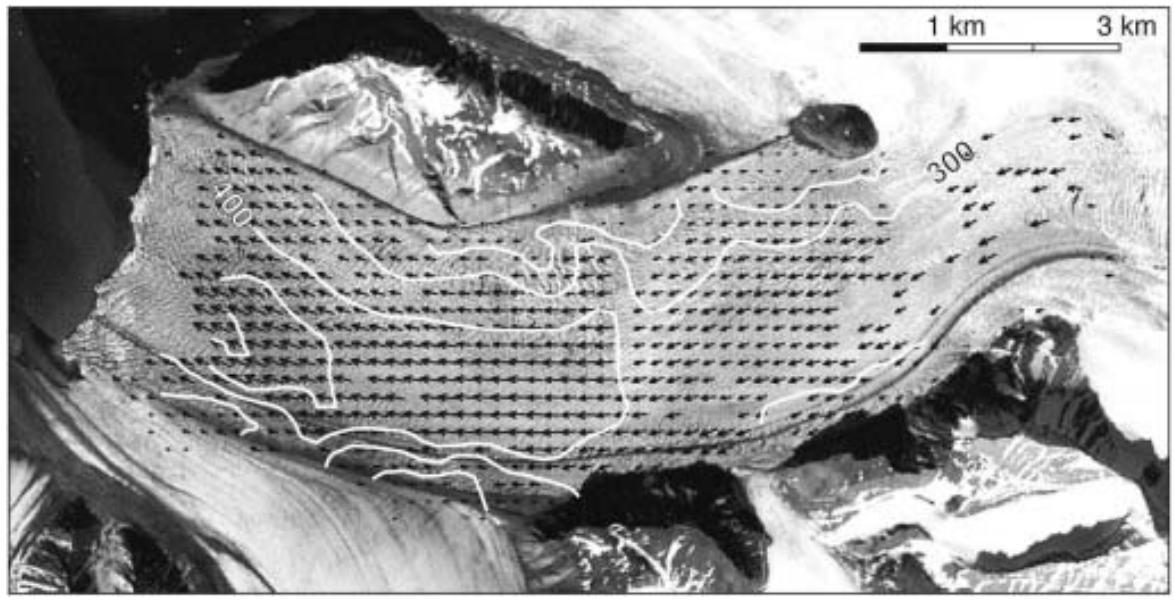

Fig. 3. Average surface velocity field for a section of Kronebreen, derived from a Landsat 7 ETM+ scene of 10 July 1999 , and ASTER scenes of 17 August 2000, 6 August 2001 and 12 July 2002. Isolines indicate ice speed in metres per year. Underlying Landsat image of 10 July 1999.

section of Kronebreen were then computed for all the scenes listed above. For image orientation, ASTER DTM generation and orthoprojection of the satellite data, the software $\mathrm{PCI}$ Geomatica Orthoengine was employed (Toutin and Cheng, 2001).

Horizontal displacements for July 1999-August 2000, August 2000-August 2001, August 2001-July 2002 and June-August 2001 were matched using the image crosscorrelation software CIAS (Kääb and Vollmer, 2000). These measurements were based on the ASTER $3 \mathrm{~N}$ bands (0.76$0.86 \mu \mathrm{m})$ and the Landsat 7 ETM+ pan band $(0.52-$ $0.90 \mu \mathrm{m})$, both having about $15 \mathrm{~m}$ ground resolution. The fact that the images were acquired from different orbits and with different cross-track pointing angles led to some remaining low-frequency distortions between the orthoimages, presumably from errors in exterior orientation. In order to avoid these distortions, the displacements were derived section-wise. For the individual sections, planimetric orthoimage-to-orthoimage affine transformations were determined from apparently stable terrain points outside the glaciers. The parameters of the section-wise transformations were then applied to correct the raw displacement vectors.

Tracking measurements were performed in a regular $200 \mathrm{~m}$ spaced grid using a chip size of 11 by 11 pixels for cross-correlation. Larger chip sizes of 13 or 15 pixels also produced good results but approximate or exceed the sample distance of $200 \mathrm{~m}$ and thus do not provide independent measurements. Significantly larger chip sizes are more affected by surface deformation between the image dates and do not necessarily produce better results. No radiometric filtering was applied to the imagery matched because a radiometric normalization is included in the algorithm used (Kääb and Vollmer, 2000). A threshold for individual correlation coefficients was used (for most image sections: 0.6), a filter including acceptance ranges for velocity direction and amplitude was applied, and a few obvious mismatches were deleted manually. The automatic measurements succeeded very well for clean ice, but not on terrain sections which were snow-covered on one or more images.

An error for individual displacement vectors in the order of the pixel size of the exploited imagery of $15 \mathrm{~m}$ was estimated from neighbourhood statistics in sections of coherent flow (e.g. differences between the raw measurements and a filtered flow field), from the residuals obtained from the above-mentioned orthoimage-to-orthoimage transformations, and from previous accuracy assessments (Kääb, 2002, 2004). For the 40 day period during summer 2001, that value corresponds to an accuracy of about $\pm 0.2 \mathrm{~m} \mathrm{~d}^{-1}$ root mean square (rms), and for the 1 year periods to about $\pm 0.02 \mathrm{~m} \mathrm{~d}^{-1}$ (cf. error bars in Figs 5-7). This accuracy estimate includes the propagation of DTM errors to horizontal shifts in the orthoimage, as far as they were captured by the inter-comparison of orthoimages for stable terrain. DTM errors on the ice and corresponding shifts in the orthimages cannot be detected easily. Here, we tried to minimize them through the above-described multi-image-level approach for ASTER DTM generation. Furthermore, no suspect local distortions, which indicate local DTM errors, were found in the velocity fields from visual inspections and neighbourhood statistics. Large velocity errors of that type, and velocity errors from mismatches are, in addition, excluded by filtering of the velocity field for direction and amplitude (see previous paragraph).

\section{FLOW FIELD}

Figure 2 shows the raw results for the measurement between 26 June and 6 August 2001. Figure 3 depicts the average of the measurements 1999/2000, 2000/01 and 2001/02, i.e. a horizontal surface velocity field July 1999-July 2002. Due to the strong surface disruption close to the calving front, measurements were possible there over the 40 day period but not for the annual time periods.

Around July 2001, maximum speeds of more than $800 \mathrm{~m} \mathrm{a}^{-1}\left(2.2 \mathrm{~m} \mathrm{~d}^{-1}\right)$ were reached just above the calving front, and a 3 year average of more than $600 \mathrm{~m} \mathrm{a}^{-1}\left(1.6 \mathrm{~m} \mathrm{~d}^{-1}\right)$. For that glacier section, Pillewizer and Voigt (1968) and Lefauconnier and others (1994) report maximum speeds of $4.5 \mathrm{~m} \mathrm{~d}^{-1}$ and a mean annual speed of $1.5 \mathrm{~m} \mathrm{~d}^{-1}$. A marked increase in speed over the entire glacier width can be observed at around $5 \mathrm{~km}$ upstream of the front, presumably associated with a subglacial ridge crossing the valley. There, at a transverse step in surface topography (cf. Fig. 7), speed 


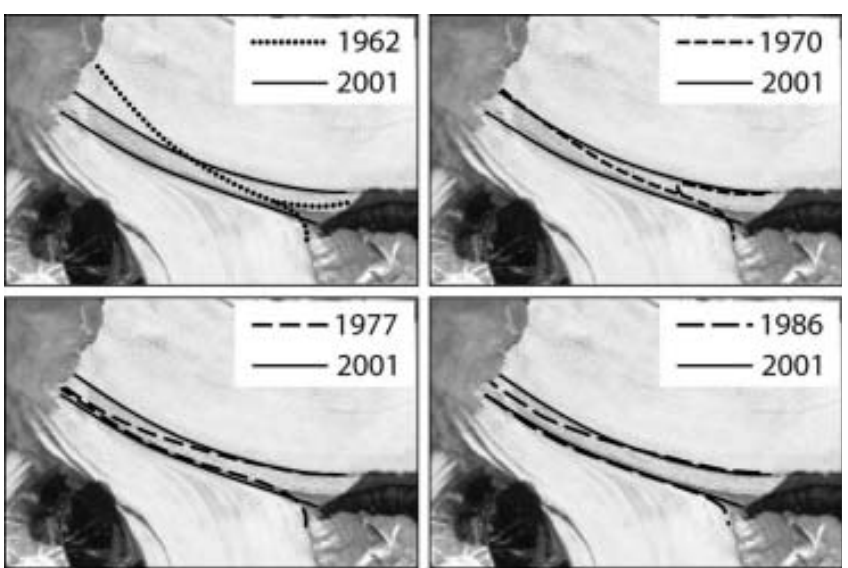

Fig. 4. Position of medial moraines between Kongsvegen and Kronebreen at selected times between 1962 and 2001. Data from Lefauconnier (1987), Melvold (1992) and this study. The shift of the moraines reflects the adjustment of ice dynamics following the 1948 surge of Kongsvegen.

increases from up to $1.3 \mathrm{~m} \mathrm{~d}^{-1}$ to up to $1.9 \mathrm{~m} \mathrm{~d}^{-1}$ within a horizontal distance of $<1 \mathrm{~km}$ (from about $0.8 \mathrm{~m} \mathrm{~d}^{-1}$ to $1.2 \mathrm{~m} \mathrm{~d}^{-1}$ for the 3 year average). Corresponding longitudinal strain rates are in the order of $0.3 \mathrm{a}^{-1}$ and more, accompanied by enhanced crevassing.

At the confluence with Kongsvegen, and up-glacier, the speed maximum of Kronebreen is shifted to its southern margin. On Kongsvegen, with speeds known to lie in the range of a few metres per year (Melvold, 1992; Melvold and Hagen, 1998), no significant movement can be detected from the $15 \mathrm{~m}$ resolution ASTER and ETM+ data. Today, the direction of the medial moraines between Kongsvegen and Kronebreen coincides with the ice-flow direction of Kronebreen. Following the 1948 surge of Kongsvegen, the position of the medial moraines continuously shifted, reflecting the adjustment of a new mass-flux equilibrium between Kronebreen and Kongsvegen ice streams (Fig. 4) (Voigt, 1966; Lefauconnier, 1987; M.J. Hambrey and others, http:// boris.qub.ac.uk/ggg/papers/full/1999/rp071999/rp07.html).

\section{Cross-profiles}

At two cross-sections, the velocity field of July 2001 provided here can be compared to data from the studies listed above (Figs 5a and 6a). The shapes of the summer 2001 (Fig. 5b), 1990 and 1986 (Fig. 5a) speed cross-profiles resemble one another, but broad variations occur, in particular toward the northern glacier margin. In 1964, the shape of the speed cross-profiles is clearly influenced by the higher ice flux from the post-surge Kongsvegen (cf. M.J. Hambrey and others, http://boris.qub.ac.uk/ggg/papers/ full/1999/rp071999/rp07.html).

Speed differences between 1999, 2000, 2001 and 2002 are significant, in particular around the central flowline of maximum speed. On an annual basis, speed differences seem to have only a slight effect on the southern margin of Kronebreen toward Kongsvegen, but rather more effect on the section north of the central flowline at $x=2 \mathrm{~km}$ in profile 1 (Fig. 5b). In contrast to the latter observation, the speed maximum during July 2001 is shifted a few hundred metres to the south. It should, however, be noted that the annual measurements between $x=1 \mathrm{~km}$ and $x=2 \mathrm{~km}$ at profile 1 were complicated by the lack of optical contrast in the images or the lack of surface features preserved over 1 year. At the upper profile P2 (Fig. 6; cf. Fig 1), most speed cross-profiles included from this and previous studies show a very similar shape, but have distinct differences in amplitude. No preferential time period for maximum spring and summer speeds is apparent (Fig. 6a).

Compared to the average annual velocities over 19992002, the summer velocities show the highest increase in speed at around $x=3 \mathrm{~km}$ in profile 2 (Fig. 6b). As a consequence, the transverse speed gradients towards the northern margin at profile 2 appear much higher in summer compared to annual averages.

\section{Longitudinal profiles}

Figure 7 shows a longitudinal profile of the velocity fields obtained in this study. A topographic profile interpolated from the 2000 ASTER DTM and selected data from the transverse speed profiles (Figs 5a and 6a) are also included.
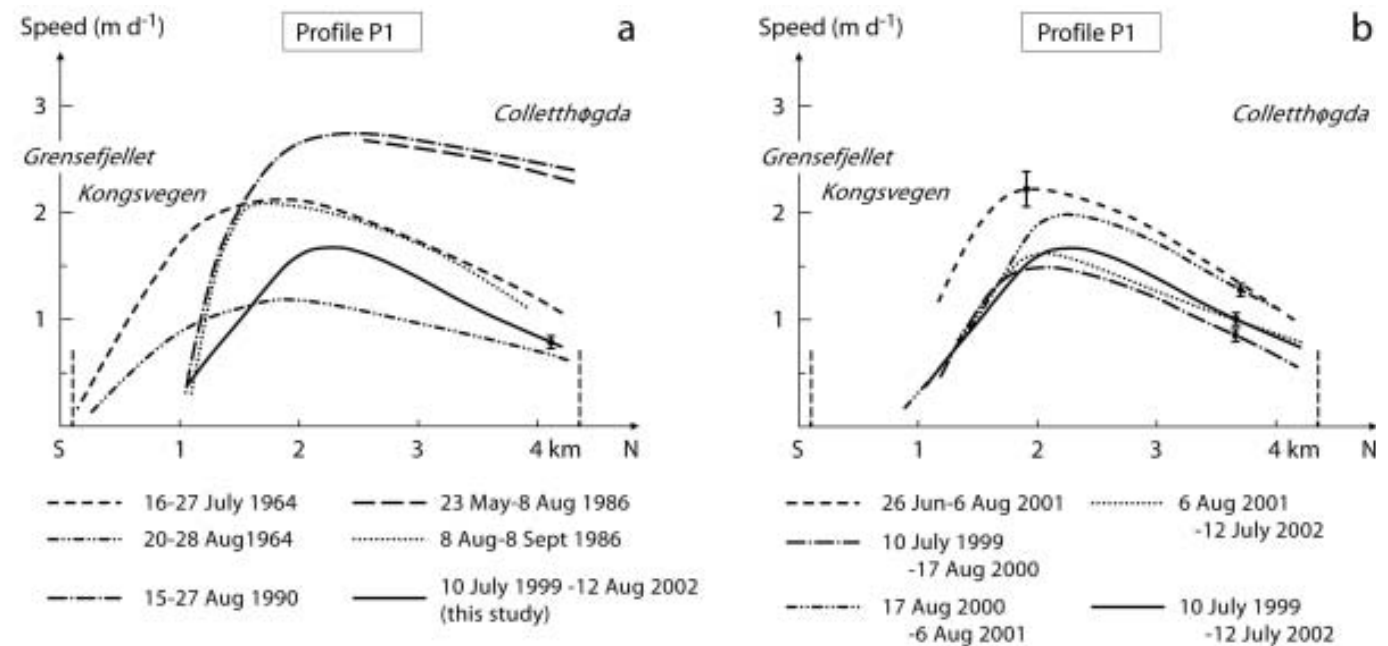

Fig. 5. Cross-profile of ice speed at position P1 (cf. Fig. 1). (a) Comparison of data from this study to previous investigations; (b) intercomparison of the data from this study. 1964 data from Pillewizer and Voigt (1968); 1986 data from Lefauconnier and others (1994) and Rolstad (1995); 1990 data from Melvold (1992); and 1999-2002 data from this study. The error bar gives the estimated accuracy for the ice speeds from the 1999-2002 measurements. 



Fig. 6. Same as Figure 5, but for position P2 (cf. Fig. 1). For 1964 in (a), speeds during 19-28 July are approximately maximum, speeds during 20-28 August approximately average and speeds during 14-25 September approximately minimum speeds of the annual cycle.

At first glance, the longitudinal speed profiles look similar, indicating that speed differences on an annual basis affect the lower $10 \mathrm{~km}$ of Kronebreen in a similar way. Shifting the profiles vertically to overlap at around $x=7 \mathrm{~km}$ shows, however, that significant differences in longitudinal gradients between the 'fast' year 2000/01 and the 'average' or 'slow' years 2001/02 and 1999/2000 are present between $x=7 \mathrm{~km}$ and $x=5 \mathrm{~km}$. Between the years investigated, strain rates differ by up to $0.04 \mathrm{a}^{-1}$, i.e. $>10 \%$ of the total strain rate in this section of Kronebreen. Below point $x=5 \mathrm{~km}$, average annual gradients are similar over 1999-2002.

\section{DISCUSSION}

Between 1999 and 2002 the annual velocities on the lower $10 \mathrm{~km}$ of Kronebreen varied by about $\pm 15 \%$ compared to the 1999-2002 average. These variations cannot be explained by the fact that the measurements were based on slightly different sections of the year (10 July-17 August and 6 August-12 July). For instance, the 1999-2000 speeds are comparably slow, although these measurements cover a longer section of the summer speed maximum than the faster 2000/01 measurements. However, the observed variations could easily be caused by a shift in timing of the summer speed maximum. A speed maximum occurring later in summer would decrease the annual speeds measured for the previous observational year stretching from summer to summer, while increasing the annual speed measured for the subsequent observational year. This behaviour can indeed be observed for the measurement periods 1999/2000 and 2000/01, and in an opposite but less pronounced way for 2000/01 and 2001/02.

For the most part, the annual speed variations between 1999 and 2002, and also the speed increase during July 2001, affected the lower $10 \mathrm{~km}$ of Kronebreen in the same way. Largest changes in longitudinal strain rates occur at the transverse step in surface topography at around $x=6 \mathrm{~km}$ in profile 3 (Fig. 7), possibly associated with a transverse bedrock riegel. If ice thickness reaches a local minimum at this location, an overall increase in speed then leads to a disproportionately large increase in longitudinal strain rates, and vice versa.
The longitudinal profiles of annual speeds are statistically highly significant with respect to their accuracy level of about $\pm 0.02 \mathrm{~m} \mathrm{~d}^{-1} \mathrm{rms}$ (see small error bar in Fig. 7). That is less the case for the summer speed measured over a 40 day period in 2001 (see error bar of $\pm 0.2 \mathrm{~m} \mathrm{~d}^{-1} \mathrm{rms}$ in Fig. 7). However, the similar shape of this profile compared to the profiles of annual speed suggests that the relative accuracy within the profiles is better than the accuracy for individual measurements given above. This effect is mainly due to the interpolation of the profiles from nearby measurement points, a procedure that reduces the influence of noise.

For the lower part of Kronebreen, Pillewizer and Voigt (1968) found in the mid-1960s that speeds showed the following seasonal variations: roughly constant speeds from October until mid-June; speed-up at the end of June to twice the average annual speed; speed decrease until the end of July toward the annual value; average annual speed in



Fig. 7. Longitudinal profile of ice speed along profile P3 (cf. Fig. 1). Data of 1999-2002 are from this study. The grey line indicates the surface topography along the profile as interpolated from the ASTER DTM generated in this study. 
August; decrease to half the annual value in September (cf. Eldhuset and others, 2003). If that seasonal cycle still applied in 2001, our measurements from 26 June to 6 August 2001 coincide with the phase of decline from maximum speeds to average speeds. The speeds observed for July would then have to be about $150 \%$ of the annual value. Here, we observed about $130 \%$ for July 2001 , i.e. a good agreement between our measurements and the abovepredicted value when taking into account the measurement accuracy achieved here.

Lefauconnier and others (2001) presume large changes in the strain-rate variation along the whole of Kronebreen throughout a year, in particular connected to the speed-up and deceleration phases. The similar shape of the longitudinal speed variations found in this study (Fig. 7) suggests that such marked changes in strain-rate regime might rather take place $>10 \mathrm{~km}$ from the front.

The summer speed-up (at least in 2001) seems to affect the lowermost $2 \mathrm{~km}$ somewhat less than the upper parts of profile 3, as shown by the shallow longitudinal gradients in the lower $5 \mathrm{~km}$ of Kronebreen which are slightly lower in July 2001 compared to annual averages (Fig. 7). The speed cross-profiles 1 and 2 indicate that the increased summer speeds (at least in 2001) are in parts accompanied by steeper speed gradients towards the glacier margins, i.e. a more pronounced block movement due to high basal sliding (cf. Lefauconnier and others, 2001).

Inter-comparing the data of profiles 1 and 2, the velocity fields obtained in this study, and additional data from the studies listed in the introduction shows that the speed variations on Kronebreen do mostly, but not always, occur synchronously at both profiles. That becomes particularly clear through the average longitudinal speed gradients between profiles 1 and 2 as depicted in Figure 7 (profile 3). As yet we have not included in our considerations the effect of the change in position of the calving front since the 1960s.

\section{CONCLUSIONS AND OUTLOOK}

This study succeeded in deriving both annual and summer velocities on Kronebreen from repeated Landsat 7 ETM+ pan and ASTER imagery. The velocity fields obtained for the lower $10 \mathrm{~km}$ of Kronebreen for 1999-2000, 2000-01, 200102 and July 2001 show, in general, good agreement with previous measurements, with, however, significant variations from year to year. From our measurements it is not clear if the observed velocity variations are due to changes in speed amplitude or due to shifts in timing of the period of maximum speeds.

At the confluence zone with Kongsvegen, the 1948 surge and, presumably, the changing position of the calving front (in advance of the 2001 position by approximately $3 \mathrm{~km}$ in the 1960s) influenced the flow field. The flow mode of Kronebreen some kilometres upstream of the front has not, however, changed substantially since the 1960s.

The combination of Landsat 7 ETM+ pan and ASTER data for the measurement of velocity fields on a fast-flowing arctic glacier proved feasible. This combination required a DTM for orthoprojection, and, in the same way, it would be easy to include data from other sensors (e.g. SPOT) in the analysis. In this study, the required DTM was produced from ASTER along-track stereo data. In cases where optical contrast was poor, a DTM derived from interferometric synthetic aperture radar (InSAR) data could be employed instead (Kääb, 2005).

Our study underlines the highly complementary character of optical and SAR methods for spaceborne DTM generation and surface displacement measurements on large glaciers. Optical methods fail at locations with insufficient optical contrast (e.g. over snow cover), but InSAR is often suited to such conditions, provided that short time bases are available. For fast ice flow and under surface melting conditions, interferometry often suffers from phase decorrelation, whereas fast terrain movement significantly improves the signal-to-noise ratio for optical methods. Thus, a complete surface velocity field of Kronebreen is now known from combining the DInSAR studies available for the upper part of the glacier (Lefauconnier and others, 2001; Eldhuset and others, 2003), and the optical image-matching study presented here.

\section{ACKNOWLEDGEMENTS}

The Landsat 7 and ASTER scenes used in this study were provided within the framework of the GLIMS project. The ASTER data are courtesy of the NASA Goddard Space Flight Center, the Ministry of Economy, Trade and Industry (METI), Japan, the Japanese Earth Remote Sensing Data Analysis Center (ERSDAC), the Japan Resources Observation System Organization (JAROS) and the US/Japan ASTER science team. We are grateful to $\mathrm{H}$. Pritchard and an anonymous referee for helpful and constructive comments. Thanks are due to T. Kellenberger and the system administration of the Department of Geography, University of Zürich, for maintaining the satellite-data processing software used.

\section{REFERENCES}

Bishop, M.P. and 16 others. 2004. Global land ice measurements from space (GLIMS): remote sensing and GIS investigations of the Earth's cryosphere. Geocarto International, 19(2), 57-84.

Björnsson, H. and 6 others. 1996. The thermal regime of sub-polar glaciers mapped by multi-frequency radio-echo sounding. J. Glaciol., 42(140), 23-32.

Dowdeswell, J.A. and T.J. Benham. 2003. A surge of Perseibreen, Svalbard, examined using aerial photography and ASTER highresolution satellite imagery. Polar Res., 22(2), 373-383.

Eldhuset, K., P.H. Anderson, S. Hague, E. Isaksson and D.J. Weydahl. 2003. ERS tandem InSAR processing for DEM generation, glacier motion estimation and coherence analysis on Svalbard. Int. J. Remote Sensing, 24(7), 1415-1437.

ERSDAC (Japanese Earth Remote Sensing Data Analysis Center). 1999a. ASTER user's guide. Part I(2). Tokyo, Earth Remote Sensing Data Analysis Center.

ERSDAC (Japanese Earth Remote Sensing Data Analysis Center). 1999b. ASTER user's guide. Part II(2). Tokyo, Earth Remote Sensing Data Analysis Center.

Hagen, J.O., O. Liestøl, E. Roland and T. Jørgensen. 1993. Glacier atlas of Svalbard and Jan Mayen. Norsk Polarinst. Medd. 129.

Kääb, A. 2002. Monitoring high-mountain terrain deformation from repeated air- and spaceborne optical data: examples using digital aerial imagery and ASTER data. ISPRS J. Photogramm. Remote Sensing, 57(1-2), 39-52.

Kääb, A. 2004. Remote sensing of mountain glaciers and permafrost creep. Zürich, University of Zürich. (Physical Geography Series 48.) 
Kääb, A. 2005. Combination of SRTM3 and repeat ASTER data for deriving alpine glacier flow velocities in the Bhutan Himalaya. Remote Sensing Environ., 94(4), 463-474.

Kääb, A. and M. Vollmer. 2000. Surface geometry, thickness changes and flow fields on permafrost streams: automatic extraction by digital image analysis. Permafrost Periglac. Process., 11(4), 315-326.

Kääb, A. and 6 others. 2003. Glacier monitoring from ASTER imagery: accuracy and application. EARSeL eProceedings, 2(1), 43-53.

König, M., J.G. Winther and E. Isaksson. 2001. Measuring snow and glacier ice properties from satellite. Rev. Geophys., 39(1), 1-28.

Lefauconnier, B. 1987. Fluctuations glaciaires dans le Kongsfjord, bai du Roi, $79^{\circ} \mathrm{N}$, Spitsbergen, analyses et conséquences. (PhD thesis, Université de Grenoble.)

Lefauconnier, B., J.O. Hagen and J.P. Rudant. 1994. Flow speed and calving rate of Kongsbreen glacier, Svalbard, using SPOT images. Polar Res., 13(1), 59-65.

Lefauconnier, B., D. Massonnet and G. Anker. 2001. Determination of ice flow velocity in Svalbard from ERS-1 interferometric observations. Mem. Nat. Inst. Polar Res. 54, 279-290.

Liestøl, O. 1988. The glaciers in the Kongsfjorden area, Spitsbergen. Nor. Geogr. Tidsskr., 42(4), 231-238.

Melvold, K. 1992. Studie av brebevegelse på Kongsvegen og Kronebreen, Svalbard. Oslo, Universitetet i Oslo. (Rapportserie in Naturgeografi 1.)
Melvold, K. and J.O. Hagen. 1998. Evolution of a surge-type glacier in its quiescent phase: Kongsvegen, Spitsbergen, 1964-95. J. Glaciol., 44(147), 394-404.

Pillewizer, W. and U. Voigt. 1968. Block movement of glaciers. Geodätische und Geophysikalische Veröffentlichungen R III.

Rolstad, C. 1995. Satellitt- og flybilder til bestemmelse av bredynamikk. (MSc thesis, University of Oslo.)

Scambos, T.A., M.J. Dutkiewicz, J.C. Wilson and R.A. Bindschadler. 1992. Application of image cross-correlation to the measurement of glacier velocity using satellite image data. Remote Sensing Environ., 42(3), 177-186.

Skvarca, P., B. Raup and H. De Angelis. 2003. Recent behaviour of Glaciar Upsala, a fast-flowing calving glacier in Lago Argentino, southern Patagonia. Ann. Glaciol., 36, 184-188.

Toutin, T. and P. Cheng. 2001. DEM generation with ASTER stereo data. Earth Observation Magazine, 10(6), 10-13.

Voigt, U. 1966. The determination of the direction of movement on glacier surfaces by terrestrial photogrammetry. J. Glaciol., 6(45), 359-367.

Wangensteen, B., D.J. Weydahl and J.O. Hagen. 1999. Mapping glacier velocities at Spitsbergen using ERS tandem SAR data. In Proceedings of International Geoscience and Remote Sensing Symposium (IGARSS '99), 28 June-2 July 1999, Hamburg, Germany. Piscataway, NJ: Institute of Electrical and Electronics Engineers, 1954-1956. 